\title{
DOD incidence in thoroughbred foals between 23 and 45 weeks of age - growth, nutrition and genetic factors
}

\author{
Joana NERY ${ }^{\text {*** }}$, Gilberto SCHELINO ${ }^{\mathrm{b}}$, Jeremiah A. O’SULLIVAN ${ }^{\mathrm{c}}$, \\ Giovanni PERONA ${ }^{\mathrm{a}}$, Domenico BERGERO ${ }^{\mathrm{a}}$ \\ ${ }^{a}$ Dipartimento di Produzioni Animali, Epidemiologia ed Ecologia, Università di Torino, \\ Via L. da Vinci, 44, 10095 Grugliasco (TO), Italy \\ ${ }^{\mathrm{b}}$ Private practitioner, Cuneo, Italy \\ ${ }^{\mathrm{c}}$ Private practitioner, Bagenalstown, Ireland
}

(Received 3 October 2005 - Accepted 7 September 2006)

\begin{abstract}
The aim of this work was to understand the extent of developmental orthopaedic disease (DOD) multifactorial aetiology factors. Growth pattern, nutritional and genetic factors were studied on a population of 89 thoroughbred foals aged between 23 and 45 weeks: growth curve characterisation, feeding plan analysis and genetic study approach to stallion progeny were accomplished in order to evaluate their influence on DOD frequency. A statistically significant difference was found between DOD positive and DOD negative foals' weight; fillies were found to be the sub-population responsible for this difference. A shortage of energy and protein was found during the period considered and there was an excess in calcium and phosphorus by the end of the period. Genetic factor analysis indicated an intensive utilisation of stallions with the higher results of DOD positive foals although the breeding system's objectives regarding this aspect remained unclear.
\end{abstract}

Developmental Orthopaedic Diseases (DOD) / osteochondrosis / growth pattern / nutrition / sire evaluation

Résumé - Incidence des DOD chez des poulains pur sang âgés de 23 à 45 semaines - croissance, nutrition et facteurs génétiques. Le but de ce travail était d'étudier les différents facteurs, parmi lesquels figurent la génétique, les facteurs alimentaires et le rythme de la croissance, à l'origine des maladies ostéoarticulaires de la croissance (Developmental Orthopaedic Diseases - DOD). L'étude a été conduite sur 89 poulains pur sang d'âge compris entre 23 et 45 semaines, pour lesquels les courbes de croissance ont été déterminées et l'analyse nutritionnelle de l'alimentation évaluée. Par ailleurs, une approche génétique incluant les performances des étalons reproducteurs dont sont issus les poulains a été faite, afin d'en évaluer l'impact sur l'incidence des DOD. Une différence statistiquement significative a été observée entre les poulains qui ont développé des DOD et ceux qui n'ont en pas développé, cette différence est à relier au sexe de l'animal, donc au poids et à l'allure de la courbe de croissance. L'analyse nutritionnelle a montré d'une part un déficit d'énergie

*Corresponding author: neryjoana@hotmail.com 
et de protéines pendant la période considérée et d'autre part un excès de calcium et de phosphore vers la fin de la même période. Bien que l'approche génétique ait révélé que les poulains les plus atteints par les DOD sont ceux issus des étalons les plus intensément utilisés, aucune indication claire concernant les choix pour un programme de sélection sur cet aspect n'a été mise en évidence.

maladies ostéoarticulaires de la croissance (DOD) / ostéochondrose / modèle de croissance / nutrition / évaluation de l'étalon

\section{INTRODUCTION}

Taking into consideration the latest research studies on developmental orthopaedic disease (DOD), the incidence in thoroughbreds is about $10 \%$ [15] but some studies have found percentages as high as around 40\% [13] in show jumpers revealing the impact of these conditions on equine production. Prevention measures regarding the multifactorial nature of DOD have been studied since 1985 [15] leading to the development of knowledge in this research area.

Developmental Orthopaedic Disease (DOD) designation was first used in 1986 by McIlwraith to define the skeletal problems affecting the growing foal associated with its development and it includes the following conditions [11]: Osteochondrosis, Physitis, Angular Limb Deformities, Flexural Deformities, Subchondral Cystic Lesions, Cervical Vertebral Malformation or Wobbler Syndrome (referred by Aldred [1]) and Cuboidal Bone Malformation.

DOD is nowadays widely considered by the bibliographic references, as a multifactorial condition and, according to Valette et al. [21], from an aetiologic point of view, it comprises a broad range of factors. The former authors have stated that there are four sets of factors that contribute to the occurrence of DOD: genetic, growth pattern, biomechanics and nutrition.

It is consensual in the scientific literature consulted that genetic factors have a major influence on DOD incidence in general, mainly between different breeds [20], and in Osteochondrosis (OCD) in particular. The practical procedures that can be useful in breeding management of DOD are, however, still limited due to a lack of research studies on this topic but Phillipson [19] has suggested that osteochondrosis incidence might be decreased via stallion selection.

Growth pattern has been considered by Valette et al. [21] as a first risk factor while McIlwraith [11] and Harris et al. [7] consider that this factor is not so evident in equines despite the results obtained with other species as the ones accomplished by Goedegebuure et al. [6]. Lewis [9] indicates that when growth speed doubles, the risk of DOD is multiplied by four to five times and that this fact is particularly significant during the first three months of the foals' life. Pagan [14] has reported a trial in Kentucky that assesses growth patterns of thoroughbreds, in which the foals' body condition score (BCS) and weights were two of the parameters measured. In this study, fillies showed a higher BCS from one until eighteen months. In a recent paper, Donabedian et al. [2] found a positive correlation for fast growth on the occurrence of some DOD, but height at withers was more correlated than body weight itself; moreover, a well balanced feeding level cannot be considered a sufficient factor, but fast development itself was found to be a factor of increased DOD occurrence.

According to Duren [3], nutrition constitutes a potential factor affecting DOD incidence and a proper balance of the growing horses' diet is fundamental. Pagan [17], however, states that nutritional intervention only helps to reduce the severity of DOD and that not all of its damage is reversible. The bibliographic references consulted indicate as follows the main nutritional 
Table I. Definition of weight subsets in the study population, female and male groups according to their DOD score classification.

\begin{tabular}{lccc}
\hline & DOD score $^{1}$ & $\mathrm{~N}$ & Mean weight \pm SD $(\mathrm{kg})$ \\
\hline Population $(\mathrm{N}=717)$ & 1 & 209 & $290.16 \pm 34.01^{\mathrm{a}}$ \\
& 2 & 271 & $295.08 \pm 31.32^{\mathrm{b}}$ \\
Female $(\mathrm{N}=367)$ & 3 & 237 & $291.70 \pm 36.71^{\mathrm{a}, \mathrm{b}}$ \\
& 1 & 103 & $284.67 \pm 31.48^{\mathrm{a}}$ \\
Male $(\mathrm{N}=350)$ & 2 & 152 & $290.93 \pm 27.90^{\mathrm{b}}$ \\
& 3 & 112 & $282.08 \pm 30.13^{\mathrm{a}}$ \\
& 1 & 106 & $295.48 \pm 35.64^{\mathrm{a}}$ \\
& 2 & 119 & $300.37 \pm 34.61^{\mathrm{a}}$ \\
\hline
\end{tabular}

a, b Means related to groups significantly different at $P<0.05$.

${ }^{1}$ Foals were classified according to McIlwraith [12] as healthy (1), with DOD (2) and with other injuries (3).

parameters that must be considered in order to control DOD incidence: (1) energy - Valette et al. [21] reports that high energy supply is the most common cause of DOD occurrence either directly (inducing high growth rates) or indirectly (an imbalance regarding the nutrients required for bone development); Ellis [4], however, stated that an undersupply of energy leads to a decrease on growth rates, and retardation in extreme cases, leading to a possible subsequent compensatory growth post under nutrition period that can enhance DOD occurrence; (2) protein - protein quantity per se does not influence DOD incidence except in cases of under nutrition, although its interaction with energy intake may raise DOD occurrence risks [4, 5]; (3) macro minerals (mainly calcium and phosphorus) - all literature references consulted highlight the danger of an excess of dietary phosphorus; Pagan [17] has highlighted the importance of the mineral ratio in the diet while the literature refers to an optimal Ca:P ratio around $1.5[3,19]$. Paragon et al. [18] has stated that lower DOD incidences were found in farms supplying a $\mathrm{Ca}: \mathrm{P}$ ratio above 2 .
The aim of this work was to give a contribution to the understanding of the extent of Developmental Orthopaedic Diseases (DOD) multifactorial aetiology considering an approach to growth pattern, genetic and nutritional factors.

\section{MATERIALS AND METHODS}

Weight measurements and X-ray examinations were considered in an 89 thoroughbred foal population at an Irish Stud (details on gender frequency are stated in Tab. I). Growth curves were built regarding different health condition statuses. Foals arrived at the stud from different proveniences between 18/08/2001 and $13 / 11 / 2001$, their dates of birth (DOB) ranged from 17/01/2001 to 18/05/2001 and their age at arrival to the stud was $23.83 \pm$ 3.58 weeks (average \pm SD). The weights were measured every two weeks from August 2001 until January 2002 (an exception was made for $25 / 12 / 2001$, the last week of 2001). The health condition classification 
was based on the radiology report that took place from 08/01/2002 to 16/01/2002.

\subsection{Radiographic assessment}

The radiology report was undertaken after the last weight measured and, based on its information, yearlings were classified according to McIlwraith [12] as healthy (1), with DOD (2) and with other injuries (3). Although there are a wide range of conditions drawn in the DOD study, the present work considered mainly the occurrence of osteochondrosis in the foals studied and the radiology report was classified in such a way that OCD and the presence of fragments, chip fractures and cysts in the joints were always considered as DOD.

\subsection{Growth pattern}

The weights considered for this study were measured every two weeks and were based on the foals' age from the 23rd to the 45 th weeks. The scale used was a four charge cell scale by omega bilance, Gallarate (MI). Foals' weight at arrival was $255.71 \pm 30.53 \mathrm{~kg}$ (average $\pm \mathrm{SD})$.

\subsection{Nutritional analysis}

Feeding analysis and collection of product specifications (ingredients, composition and recommended dosage) were performed, in order to obtain all the available data concerning the influence of the feeding programme on DOD incidence in the studied population during the studied period. Details on the feeding programme are further described in the results. Animals were kept on pasture during the study period. SIRE horse feeding software (by Rostagno and Bergero, 2003), based on the French nutrition tables [10], was used in order to assess the balance between the requirements and supply of energy, protein, calcium and phosphorus.

\subsection{Genetic factors}

Breeding sires at the origin of the studied population were studied in order to understand the extent of the genetic factors on DOD incidence. Stallions were divided into four groups regarding two criteria: the number of foals from the study population and foal DOD incidence. The population considered included 92 foals (some foals did not have weight records for the mentioned ages but the stallion used and the radiological report data were available). Accordingly, the sires were divided into more and less than four foals per stallion (no stallion has shown a progeny of four foals) and progeny quantity scored as DOD positive and negative.

\subsection{Statistical analysis}

\subsubsection{Growth pattern statistical analysis}

Univariate analysis of variance was used to search for significant differences on the independent variable weight regarding the factors age, sex and health status of individuals among the population and interactions were also studied. The Tukey post hoc test was used to evaluate the differences among the different groups. Following the post hoc test, homogeneous subsets were defined for health status. Growth Curves were obtained for eight groups: healthy (1), DOD positive (2), foals with other injuries (3) and DOD negative $(1+3)$, both for males and females. The models used to determine the growth curve for the eight groups mentioned were quadratic; linear models were also controlled. 


\subsubsection{Genetic factor statistical analysis}

The Chi-square test was used, in order to analyse if there was a significant difference among the groups mentioned, since the information available relied on sire attribute frequencies. The independent variable percentage of DOD positive progeny was statistically analysed with univariate analysis of variance according to sire feature factors such as height, age at first race, years racing, total earnings, number of starts, number of wins and number of second places. The information regarding sire factors were collected on official internet websites. This analysis was performed in order to set the relations among the factors that may have been related to the choice of stallions for the breeding programme.

\section{RESULTS}

\subsection{Growth pattern analysis}

Univariate analysis of variance shows an absolute significance between the weights measured and sex $(P<0.001)$ and weeks of age $(P<0.001)$, a high significance between weights and the interaction between health status and sex $(P=0.035)$ and an intermediate value for the relation between weight and health status $(P=0.087)$. The analysis showed no significance between weight and the interaction of the factors time and health status as well as the interaction between health status, sex and age of the foals. The frequencies verified for healthy, DOD positive and foals with other injuries in the population were $29.15 \%, 37.80 \%$ and $33.05 \%$ respectively. The frequencies verified for healthy, DOD positive and foals with other injuries in the female population were $28.07 \%, 41.42 \%$ and $30.52 \%$ respectively while in the male population the frequencies mentioned were correspondingly $30.29 \%, 34.00 \%$ and $35.71 \%$. The post hoc test shows a significant difference between DOD positive (2) and the DOD negative groups ( 1 and 3 ) in the population but this difference was found to have its origins in the female population since there was no significant difference among the groups settled in the male population. The results obtained for the different homogeneous subsets defined among the population in general and for the female and male groups in particular are stated in Table I. According to these results, a single subset in the male population for the different health statuses was established, which indicates that there are no differences between the weight means for the different health statuses, and two distinct subsets were established for the female population dividing it in DOD positive and DOD negative fillies.

The groups defined primarily as 1 and 3 were not eliminated from the growth curves because, according to the features observed for the female population, they were significantly different throughout the period considered.

\subsubsection{Growth curves}

Considering the values obtained for the subsets that regard the foals' age as well as the division of the population into four groups leads to the assembly of eight growth curves: groups 1, 2, 3, 1+3 both for colts and fillies. The higher $r^{2}$ value achieved for the quadratic method as well as a lower standard error of estimation (SEE) verified in the mentioned method has proven the methodology option to satisfactorily fit the growth pattern analysis. The parameters defined led to growth curves defined by the following systems in which BW refers to body weight in kilograms, $t$ defines age in weeks, $\mathrm{F}$ and $\mathrm{M}$ refers to the female and male population respectively and 1, 2, 3 and $1+3$ identifies the DOD classification previously mentioned: 


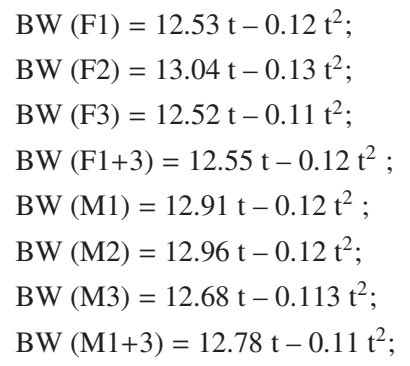

The mentioned growth curves verified for each age category are presented in Figures 1 and 2 for females and males respectively.

\subsection{Nutritional analysis}

The foals were fed mostly grass, hay and concentrate feeding stuff supplement in different quantities for the period of time spent in the stud. The pasture available was meadow grass composed of gramineae, clover and very few different kinds of grasses and its chemical analysis is given in Table II. It was considered that the foals consumed $25 \mathrm{~kg}$ of pasture (as fed) at the beginning of the period and $20 \mathrm{~kg}$ by the end of the period mentioned. The previously mentioned level of grass intake was assumed on the basis of the pasture yield that decreased during the period considered and the overall dry matter intake of the studied foals. The hay supplied to the foals was first cut alfalfa and its composition can be assessed in Table II. The daily concentrate feeding stuff

$$
\begin{array}{ll}
r^{2}=0.998 ; & \text { SEE }=14.19 \\
r^{2}=0.998 ; & \text { SEE }=13.42 \\
r^{2}=0.997 ; & \text { SEE }=15.09 \\
r^{2}=0.997 ; & \text { SEE }=14.84 \\
r^{2}=0.996 ; & \text { SEE }=18.18 \\
r^{2}=0.997 ; & \text { SEE }=16.57 \\
r^{2}=0.994 ; & \text { SEE }=23.33 \\
r^{2}=0.995 ; & \text { SEE }=21.14
\end{array}
$$

quantities supplied were $1.8 \mathrm{~kg}$ at arrival of the foals to the Stud and this quantity was progressively increased to $3.6 \mathrm{~kg}$ at the end of the period mentioned. The feeding stuff categories of ingredients mentioned in the product specifications are cereal grains, oilseed products and by-products, sugar products and by-products, cereal grain products and by-products, minerals, legume seed products and by-products, dried forages and oil seeds and its chemical composition was obtained by sampling and laboratory analysis. These values are shown in Table II. The foals were also fed supplements; among them some were formulated for mobility improvement and joint injury prevention and their composition included mainly glucosamine, methylsulfonylmethane and chondroitin sulphate. Salt blocks were available to all foals while feeding in the stalls.

Although the foals' nutritional requirements considered were equal for both the beginning and end of the period considered, as also indicated by the nutritional requirement tables of INRA, due

Table II. Feeding analysis undertaken for the products used in the foal feeding programme; data are shown as percentage of dry matter.

\begin{tabular}{lcccccc}
\hline Sample & $\begin{array}{c}\text { Moisture } \\
(\%)\end{array}$ & $\begin{array}{c}\text { Crude Fibre } \\
(\% \mathrm{DM})\end{array}$ & $\begin{array}{c}\text { Crude Protein } \\
(\% \mathrm{DM})\end{array}$ & $\begin{array}{c}\text { Ether Extract } \\
(\% \mathrm{DM})\end{array}$ & $\begin{array}{c}\text { Crude Ash } \\
(\% \mathrm{DM})\end{array}$ & $\begin{array}{c}\text { NDF } \\
(\% \mathrm{DM})\end{array}$ \\
\hline Grass & 15.32 & 23.06 & 15.41 & 2.50 & 9.35 & 30.85 \\
Hay & 12.38 & 32.55 & 4.12 & 1.38 & 3.02 & 53.17 \\
Concentrate & 10.25 & 9.58 & 12.91 & 3.18 & 6.46 & 17.63 \\
\hline
\end{tabular}


Table III. Nutritional daily balance for foals at arrival.

\begin{tabular}{lccccccc}
\hline & Energy $(\mathrm{UFC})$ & $\mathrm{MADC}(\mathrm{g})$ & $\mathrm{Ca}(\mathrm{g})$ & $\mathrm{P}(\mathrm{g})$ & $\mathrm{Mg}(\mathrm{g})$ & $\mathrm{Na}(\mathrm{g})$ & $\mathrm{DM}$ \\
\hline Requirement & 5.80 & 630.00 & 41.00 & 23.00 & 10.00 & 13.00 & 6.00 \\
Supply & 4.44 & 417.4 & 43.18 & 24.38 & 11.82 & 6.26 & 6.32 \\
\hline
\end{tabular}

Table IV. Nutritional daily balance for foals at the end of the period.

\begin{tabular}{lccccccc}
\hline & Energy (UFC) & MADC $(\mathrm{g})$ & $\mathrm{Ca}(\mathrm{g})$ & $\mathrm{P}(\mathrm{g})$ & $\mathrm{Mg}(\mathrm{g})$ & $\mathrm{Na}(\mathrm{g})$ & $\mathrm{DM}$ \\
\hline Requirement & 5.80 & 630.00 & 41.00 & 23.00 & 10.00 & 13.00 & 6.00 \\
Supply & 5.58 & 567.80 & 56.36 & 33.76 & 14.64 & 6.52 & 6.93 \\
\hline
\end{tabular}

to the short period considered, the supply has changed during this period since in practice the foals feeding plan entails the mentioned changes. Tables III and IV describe the rationing evaluation made with the software mentioned in the Materials and Methods section. All nutritional factors were analysed and kept in consideration the requirements for an average foal and a different supply level at the beginning and end of the period at the stud.

It is possible to infer from Tables III and IV that the $\mathrm{Ca}: \mathrm{P}$ ratio was 1.8 and 1.7 at arrival and at the end of the period respectively.

\subsection{Genetic factor analysis}

The data collected and subsequent statistical approach was based on the availability of data, which led to a sub population that considered 17 out of $40(43 \%)$ stallions representing 44 out of $92(48 \%)$ foals.

The Chi-square value obtained was 5.845 and the $P$-value considering 1 degree of freedom was 0.016 . Therefore, there is a relation between the number and the score of the foals per stallion. In fact, $15 \%$ of the total number of stallions considered was used to produce $33.70 \%$ of the total number of foals from which $64.52 \%$ and $35.48 \%$ were classified as DOD positive and negative respectively. From the 15 stallions with results of more than half DOD positive progeny (that resulted in a total of 27 DOD positive foals), $25 \%$ were included in the group of stallions with more than 4 foals $(59.26 \%$ of the mentioned 27 DOD positive foals) and the remaining $75 \%$ were included in the sire group with less than 4 foals $(40.74 \%$ of the mentioned 27 DOD positive foals).

The use of the univariate analysis of variance led to no conclusions regarding the choices made for the breeding programme. Thus, none of the stallion features mentioned in our study had any relation with the frequency of DOD positive results on the foals' population.

\section{DISCUSSION}

\subsection{Growth pattern}

According to the results regarding growth pattern factors, it is possible to set differences between different groups within the studied population. Assessing the univariate analysis of variance it is possible to understand that, in this study, statistically significant differences were found regarding weights measured and the interaction between health status and sex, while the factor time (age in weeks) was shown to have no influence on weight considering the interactions of this factor (age) with all 


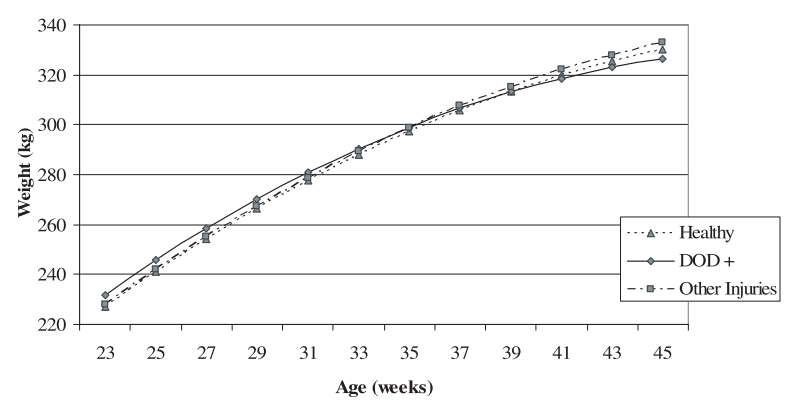

Figure 1. Female growth curves from 23 to 45 weeks of age according to the different health conditions.

the others mentioned (sex and health status). The other statistically significant values were related to weight and foal sex and age. This obviously translates the relation between weight and age as well as weight and sex, which has been widely studied and ultimately leads to the understanding of growth patterns illustrated by growth curves. The relation between weight and health status showed that the sub-populations classified as 1 and 2 are statistically different, with a weight difference of $5 \mathrm{~kg}$ (Tab. I), while population 3 had similar features to both groups 1 and 2 regarding health status. According to the literature, several sources $[1,8,16$, 21] have stated different growth patterns for positive and negative DOD foals. The differences found in literature review [15] set a difference of $17 \mathrm{~kg}$ for approximately 17 weeks of age and $12 \mathrm{~kg}$ for 43 weeks taking into consideration the average population weight. This indicates that even though the difference found in the present study between population groups 1 and 2 was low compared with the literature references, it is statistically significant and corroborates the conclusions regarding the influence of growth pattern in DOD incidence. In conclusion, this study shows that weight differs between DOD positive and DOD negative foals during the period of 23 to 45 weeks of age indicating an influ- ence of growth pattern on DOD incidence. A closer approach considering the factor foal's sex allows the conclusion that fillies had a clear distinction between health status subsets in which groups 1 and 3, with correspondingly average weights of $284.67 \pm 31.48 \mathrm{~kg}$ and $282.08 \pm 30.13 \mathrm{~kg}$, were considered in the same homogeneous subset while group 2, with an average weight of $290.93 \pm 27.90 \mathrm{~kg}$, was considered in a different subset. Colts showed no differences between the different groups settled by the health status classification. Thus, regarding the growth curves, the female population showed statistically significant results regarding DOD classification while the male population has only one subset considering health condition as shown in Figures 1 and 2. In fact, the feeding plan at a practical level does not take into consideration the different growth patterns of fillies and colts, which means that, at a nutritional level, fillies are probably overfed (associated to higher DOD occurrence in the literature review) while colts are fed at an adequate or lower level regarding their requirements. The fillies higher BCS stated in the literature review also reveals a feeding inadequacy to foal's sex and this is the reason for a higher DOD incidence in the female population. Growth curves and their equations have shown that weights tend to reach similar values for 
DOD positive and DOD negative foals at the end of the period considered. In fact, differences between health status groups at arrival are much more evident than at the end of the period as visible in the growth curves presented (Figs. 1, 2). This decrease between differences in weights among health status groups is probably due to nutritional factors discussed further in this chapter. Taking into consideration the constant environmental conditions as well as the literature references regarding aetiological factors, the possible causes for this tendency rely basically on nutritional factors since foals were submitted to the same conditions leading to expected maintenance of weight differences among DOD classification groups.

\subsection{Nutritional factors}

Regarding nutritional analysis, it is possible to observe that both results at the beginning and at the end of the period at the stud show a clear shortage supply of energy and protein. According to the literature [4, $12,17,21]$ high-energy diets are a major factor contributing to higher DOD incidence due to several aspects explained previously. However, Ellis [4] has also mentioned the deleterious effect that energetic undersupply may have by promoting consequent compensatory growth. According to the results stated, energy supply has no influence on the period studied since it shows lower amounts relative to the foals' demand. It is also important to underline that it would be advisable to restructure the nutritional plan supplied to the population studied since, as referenced previously, it will promote a consequent compensatory growth that will lead to DOD incidence increase. It would be useful to follow the studied foals' results for a wider period in order to assess the effects that the presented feeding plan will have on the future health condition of these animals. As for protein, it has been stated previously in the introduction $[1,4,12,21]$ that protein per se has no influence on DOD incidence; it is necessary for undernutrition of this element to occur or to have a dietary protein/energy imbalance (particularly with an excess of energy) in order to have an increase in DOD incidence. The results presented have shown that, even though protein requirements were not fulfilled by supply, there were no situations of under nutrition, neither at the beginning nor at the end of the studied period. The other condition mentioned (imbalance relative to energy supply) was not verified in the results presented (as stated, energy and protein supply were both lower regarding foals' requirements). In conclusion, protein content in the diet did not constitute the cause of DOD incidence in the studied population. The main mineral factors regarding DOD incidence stated in the literature review (calcium and phosphorus) were shown to be supplied in accordance with or higher to the requirements calculated by the software used. In the literature, it is stated that foals do not tolerate an excess of phosphorus and that calcium excess constitutes a controversial question regarding its influence on DOD incidence. Although the initial feeding plan presented for calcium and phosphorus has shown an adequate supply of minerals, at the end of the period there is an evident higher supply of both minerals relative to foals' requirements. Pagan [17] has also stated that the ratio between the two minerals discussed "may be as important as the actual amount of individual minerals in the ration" and, according to the results, the Ca:P ration in the feeding plan presented was 1.8 and 1.7 in the beginning and at the end of the period studied respectively. According to the references mentioned, the ratio found was slightly higher than the one recommended. Considering all the mineral results analysed, it is possible to conclude that the minerals might contribute slightly to the DOD 
Male Growth Curves

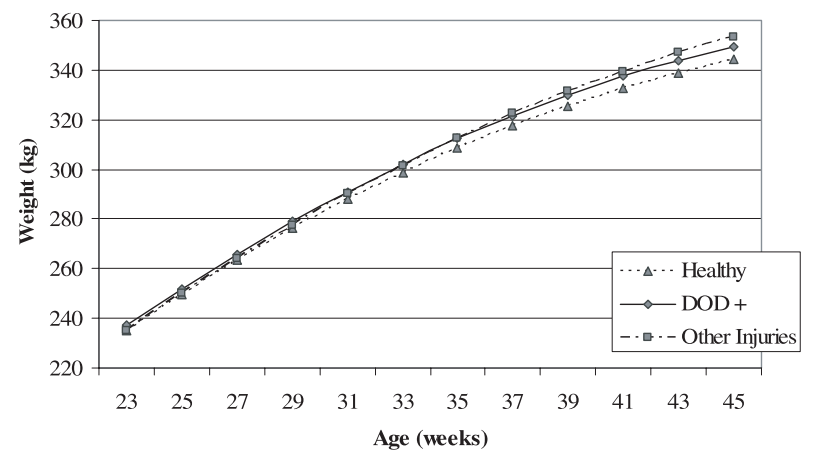

Figure 2. Male growth curves from 23 to 45 weeks of age according to the different health conditions. incidence verified. The results show that calcium and phosphorus supply and ratio are excessive but the minor difference relative to the reference values for both parameters does not indicate an unequivocal relation to DOD incidence. Thus, it is questionable whether the verified DOD occurrence relies on calcium and phosphorus supply in the studied population.

\subsection{Genetic factors}

Although there is statistical evidence of genetic factors influencing the DOD incidence in this study, the reason why the most intensively used stallions are the ones that show higher DOD positive foals in their progeny was not found. Based on the literature review, progeny evaluation was attempted in order to assess the influence of the level of stallion selection in DOD incidence. The results have shown that the factors number of foals produced by each stallion (classified as less and more than four) and DOD classification (positive and negative) were closely related. According to the expected frequencies for factor interactions, the values obtained for the classification of DOD positive and more than four foals per stallion and DOD negative and less than four foals per stallion were lower than the frequencies occurring while expected frequencies for DOD negative and more than four foals per stallion and DOD positive and less than four foals per stallions were higher than the frequencies occurring. This indicates that, with a statistical significance between events, in fact DOD positive foals were mainly bred from stallions that showed a more intensive utilisation in the breeding programme while stallions with lower DOD progeny incidence were less explored. Taking into consideration the results explained, the study guidelines focussed on evaluating the reasons behind the breeding choices undertaken. Although statistical analysis at this level has shown no significance between the factors considered and DOD incidence, which means that a closer evaluation on the breeding programme should be accomplished in order to understand at which level the intervention should be undertaken to lower the DOD incidence, the results presented point out a critical point in the population regarding DOD incidence, which relies on genetic factors. An appropriate progeny evaluation regarding the stallions used in the breeding programme would be advisable taking into consideration the conclusions reached in the present study. In the short term, a more heterogeneous use of stallions would be advisable in order to minimise the deleterious effects on foal populations produced regarding DOD incidence, since the results have shown a more intensive utilisation of 
stallions susceptible to produce DOD positive foals.

\section{REFERENCES}

[1] Aldred J., Developmental Orthopaedic Disease in Horses, Rural Industries Research and Development Cooperation, University of Sydney, Department of Animal Science, Australia, 1998.

[2] Donabedian M., Fleurance G., Perona G., Robert C., Jacquet S., Denoix J.-M., Lepage O.M., Trillaud-geyl C., Leger S., Ricard A., Bergero D., Martin-Rosset W., Effect of fast vs. moderate growth rate related to nutrients intake on developmental orthopaedic diseases in horses, Anim. Res. 55 (2006) 471.

[3] Duren S.E., Delivering Essential Nutrients to Young, Growing Horses, in: Pagan J.D. (Ed.), Advances in Equine Nutrition, Kentucky Equine Research Inc., Nottingham University Press, 2000, pp. 421-435.

[4] Ellis A., Nutrition and the Development of Osteochondrosis in Foals, Project Report: Vpa-01-11, Wageningen UR, The Netherlands, 2001.

[5] Gibbs P.G., Sigler S.H., Goehring T.B., Influence of diet on growth and development of yearling horses, J. Equine Vet. Sci. 9 (1989) 215-218.

[6] Goedegebuure S.A., Hani H.J., van der Valk P.C., van der Wal P.G., Osteochondrosis in six breeds of slaughter pigs. I. A morphological investigation of the status of osteochondrosis in relation to breed and level of feeding, Tijdschr Diergeneeskd, 1980.

[7] Harris P., Staniar W., Ellis A.D., Effect of exercise and diet on the incidence of DOD, EAAP meeting, Bled, Slovenia, H2, 7, 1-14, 2004.

[8] Jeffcott L.-B., Osteochondrosis in the horse, Searching the key for pathogenesis, Equine Vet. J. 23 (1991) 331-338.

[9] Lewis L.-D., Developmental orthopedic diseases in horses, in: Feeding and care of the horse, Lea and Febiger Book, 2nd ed., 1995, pp. 277-288.

[10] Martin-Rosset W. (Ed.), L'alimentation des chevaux, INRA, Paris, 1990.

[11] McIlwraith C.W., The Equine Skeleton: How does bone grow and how do abnormalities in the developmental process affect soundness? in: Pagan J.D. (Ed.), Advances in Equine Nutrition, Kentucky Equine Research Inc., Nottingham University Press, 2000, pp. 383406.
[12] McIlwraith C.W., Overview of Bone Disease, Kentucky Equine Research Nutrition Conference, USA, 2003.

[13] Miliani A., Bergero D., Salomoni M., Osteocondrosi ed Alimentazione: Effetto di Diversi Strategie Dietetiche in Puledri da Salto Ostacoli Allevati in Italia, Edizioni SCIVAC, Italia, Ippologia, Anno 5, No. 2, 1994.

[14] Pagan J.D., A summary of growth rates of thoroughbreds in Kentucky, in: Pagan J.D. (Ed.), Advances in Equine Nutrition, Kentucky Equine Research Inc., Nottingham University Press, 2000, pp. 449-455.

[15] Pagan J.D., The incidence of Developmental Orthopedic Disease (DOD) on a Kentucky Thoroughbred Farm, in: Pagan J.D. (Ed.), Advances in Equine Nutrition, Kentucky Equine Research Inc., Nottingham University Press, 2000, pp. 469-475.

[16] Pagan J.D., Managing Growth for Different Commercial End Points, in: Proceedings of the 2003 Equine Nutrition Conference - Growth and Development of the Equine Skeleton, Sydney, Australia, 2003, pp. 74-83.

[17] Pagan J.D., The Role of Nutrition in the Management of Developmental Orthopedic Disease, in: Proceedings of the 2003 Equine Nutrition Conference - Growth and Development of the Equine Skeleton, Sydney, Australia, 2003, pp. 40-56.

[18] Paragon B.-M., Valette J.-P., Blanchard G. Wolter R., Alimentation et statut ostéoarticulaire du cheval en croissance : Résultats du suivi 76 yearlings issus de 14 élevages en région Basse-Normandie, $27^{\mathrm{e}}$ journée de la recherche équine, Les Haras Nationaux, INRA, 2001.

[19] Philipsson J., Pathogenesis of Osteochondrosis - Genetic Implications, in: Joint Disease in the Horse, WB Saunders Company, Philadelphia, 1996, pp. 359-362.

[20] Valette J.-P., Denoix J.M., Boulet C., Monnet Y., Pathologie ostéo-articulaire juvénile : Bilan de l'étude sur 246 poulains de 1 et 2 ans provenant de la région de BasseNormandie, $26^{\mathrm{e}}$ journée de la recherche équine, Les Haras Nationaux, INRA, 2000.

[21] Valette J.-P., Paragon B.-M., Blanchard G., Robert C., Denoix J.-M., Feeding Practices and Prevention from Development Related Diseases, 2nd European Workshop on Equine Nutrition - The Growing Horse: Nutrition and Prevention of Growth Disorders, Dijon, France, 2004, pp. 297300 . 